\title{
Research on the Causes and Influencing Factors of Malodor in Suzhou Industrial Park
}

\author{
Yuefang Zhu' ${ }^{1, a}$, Lan Wei $\mathrm{i}^{2, \mathrm{~b}}$, Jiabin Wang ${ }^{2, \mathrm{c}}$, Liang Sun ${ }^{3, \mathrm{~d}}$, \\ Jiayue $\mathrm{Xu}^{4, \mathrm{e}}$ and Weilin $\mathrm{Shi}^{\mathrm{2}^{*}, \mathrm{f}}$ \\ ${ }^{1}$ Suzhou Environmental Monitoring Center, Suzhou, 215004, Jiangsu, China \\ ${ }^{2}$ Suzhou University of Science and Technology, Suzhou, 215009, Jiangsu, China \\ ${ }^{3}$ Suzhou Industrial Park Environment Supervising Brigade, Suzhou, 215027, Jiangsu, China \\ ${ }^{4}$ Suzhou Foreign Language School, Suzhou, 215011, Jiangsu, China \\ aemail: zhuyuefang0216@163.com, bemail: 1374179300@qq.com, 'email: 404384100@qq.com, \\ demail: sl@siphjjc.com, eemail: 514309566@qq.com, 'email: weilin-shi@163.com
}

Keywords: Malodorous, Causes of pollution, Diffusion, Factors, Suzhou Industrial Park.

Abstract. On the basis of paper reading and empirical investigations, this thesis searches the types of malodor substances, distribution, and causes. Furthermore, the studies of climate and terrain of the area are carried out, including the influence rules on malodor from the seasons and weather so that the influential factors of malodor spreading are analyzed. Finally, the conclusion is reached that the malodor is mainly produced by enterprises in spraying industry, electronica processing industry, new material processing industry, food processing industry and the influential factors of malodor spreading in Suzhou Industrial Park are wind direction and speed, air temperature, rainfall, atmospheric stability, urban heat island effect, and buildings. The main control measures also lie in the control of pollution sources.

\section{Introduction}

Malodor is a kind of gas which makes people feel uncomfortable, and it is also a collective of smell that all people disgust about, which could be manifested by human sense of smell and feel ${ }^{[1]}$. The so-called malodor pollution refers to all the gaseous which stimulate humans' olfactory organ and make people feel unpleasant, even damage people's living environment ${ }^{[2]}$.Papers published at home and abroad commonly define malodor as: The collective of smells which can stimulate the human olfactory organ and cause unpleasant feeling or make people disgust, and even make people sick ${ }^{[3]}$.The cause and diffusion of malodor in Suzhou Industrial Park has aroused greater social repercussions and complaints, urgent measures should be taken to put forward malodor pollution control and governance countermeasures, such as analyzing pollutants, investigating the cause of pollutants, and analyzing the diffusion pathways and influencing factors. This paper had chosen one typical malodor pollution area to carry out pollution investigation, where malodor pollution is concentrated, and repercussions are more intense, what is more, we analyzed its influencing factors.

\section{Research area and methods}

\section{Research area}

Yonghewan Garden Community, Suzhou Industrial Park is our investigate and research area, because there are many kinds of pollutions, and malodor pollution is obvious. The object of this survey is industrial enterprises of whom emission malodor pollutions. Based on the type of production of surrounding enterprises, they can be classified as spraying industry, electronica processing industry, new material processing industry, food processing industry. We have divided our research field into two regions, the north part is community and an Industrial Square, east to Zhu street, west to Weisheng Road, south to Loujiang river, north to Shanghai-Nanjing line; The south part of this research area is 
the export processing zones, east to Shanghai-Nanjing highway, west to Weisheng Road, south to modern Avenue, North to Loujiang river, $12 \mathrm{~km}^{2}$ in total as the Fig. 1 shows.

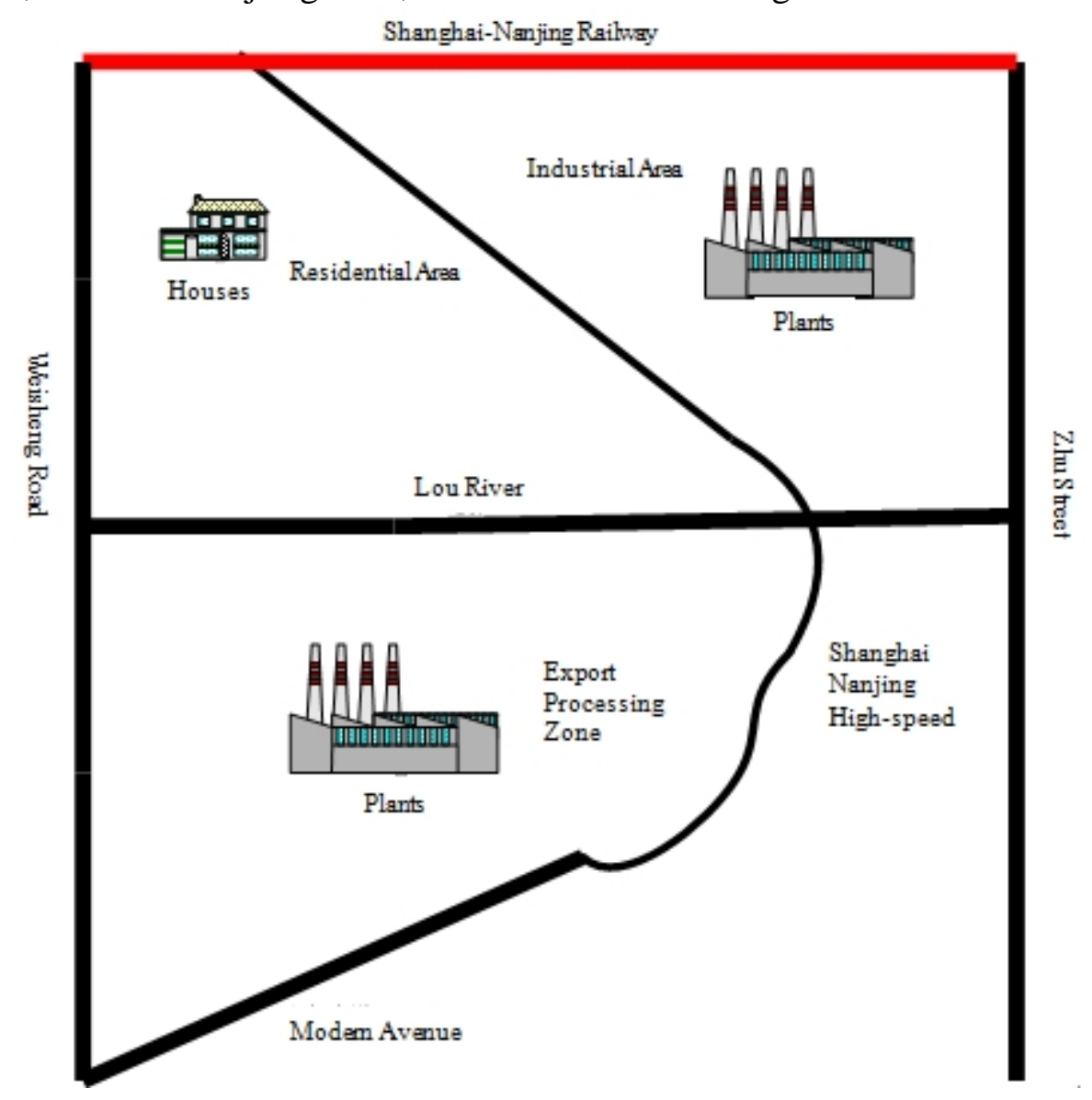

Fig. 1. Schematic of research area

\section{Research methods \\ Questionnaire}

This survey had used a questionnaire method, considering the occupation, professional background, expression skills, affecting degree and other factors, we closed Yonghewan residents for the survey, issuing, collecting questionnaires, a total of 50 questionnaires were distributed.

\section{Data query}

Another method used in this survey is data query, via the access of Internet and books, adding the information provided by the Meteorological Center Park, finishing the analysis.

\section{Site monitoring}

Choose spraying industry, electronica processing industry, new material processing industry, food processing industry in the research area to sampling and analysis, monitoring indicators are the malodor concentration and total non-methane hydrocarbons. While the industrial areas and residential community were carried out unorganized exhaust gas sampling, using a gas chromatography / mass full scan qualitative and quantitative to analyze.

\section{Results of investigation}

\section{Results of the questionnaire}

Fill in the feedback survey on-site after combing analysis, we have 50 valid questionnaires. The questionnaire is mainly about the frequency of the malodor, the season when malodor mostly happened during the year, the time when malodor mostly happened during the day, the main character of the malodor, wind direction and speed. In addition to a multiple-choice of malodor characteristics, the other four are single option, From the statistical results, we can see that: about 86 percent of residents 
believed that there is a high incidence of occur malodor, but they do not clear what kind of odor it is, 72 percent of residents believe that the smell of paint fumes is a major, it also smells like a mixing of oil and sour taste, and the frequency of occurrence of malodoris more obvious in spring and autumn, in the evening mostly, Detailed survey results are shown in Table 1.

Table 1. Questionnaire results Sheet

\begin{tabular}{ccccc}
\hline Contents & Options & $\begin{array}{c}\text { Number of } \\
\text { people }\end{array}$ & $\begin{array}{c}\text { Number of } \\
\text { people in total }\end{array}$ & proportions \\
\hline \multirow{2}{*}{ The frequency of } & Infrequent(Once a month) & 5 & 50 & $10 \%$ \\
malodorous & Sometimes(Once a week) & 27 & 50 & $54 \%$ \\
& Frequent(Once a day) & 16 & 50 & $32 \%$ \\
Most malodorous & always & 2 & 50 & $4 \%$ \\
season & spring & 29 & 50 & $58 \%$ \\
& summer & 2 & 50 & $4 \%$ \\
Most malodorous & autumn & 14 & 50 & $28 \%$ \\
time & mornter & 5 & 50 & $10 \%$ \\
& noon & 7 & 50 & $14 \%$ \\
The main & night & 2 & 50 & $4 \%$ \\
character of & Paint taste & 41 & 50 & $82 \%$ \\
malodor & Injection taste & 73 & 50 & $46 \%$ \\
Whether wind & Sour & 12 & 50 & $14 \%$ \\
direction and & Oil odor & 15 & 50 & $24 \%$ \\
speed have impact & Composite stomach & 47 & 50 & $30 \%$ \\
on malodor & & & 50 & $94 \%$ \\
\hline
\end{tabular}

\section{Results of the query data}

Suzhou Industrial Park, which is located in the subtropical humid monsoon climate zone, hot and rainy in summer, mild and dry in winter, so four seasons can be distinguished clearly ${ }^{[4]}$, in terms of wind direction, there is a huge difference between summer and winter. And its' annual precipitation is generally more than $1000 \mathrm{~mm}$, mostly in the summer, and winter is very dry.

We have made some statistics according to Suzhou City Station 2013 ground meteorological observation data on local temperature, humidity, wind speed, wind direction, wind frequency.

\section{Temperature}

The highest temperature occurs in July and August every year, generally above 30 degrees, and the lowest temperature occurs in January, generally below 5 degrees, in the rest of the month, the temperature is more comfortable to live, generally between 12 degrees to 25 degrees. Local monthly annuals average temperature change is shown in Fig. 2. 


\section{Temperature ( $\left.{ }^{\circ} \mathrm{C}\right)$}

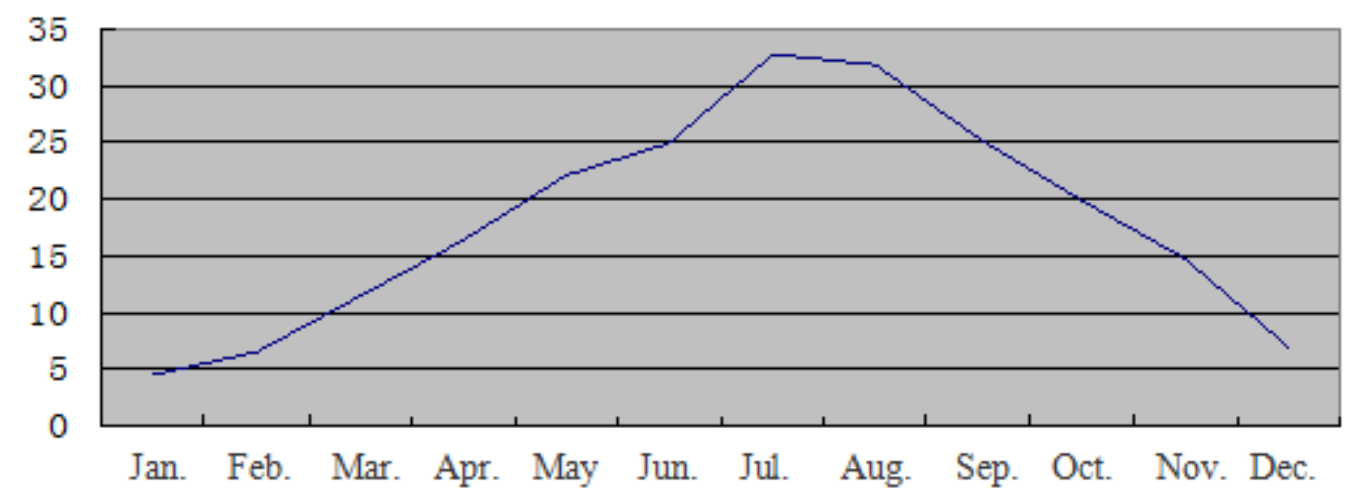

\section{Wind speed and direction}

Fig. 2. The monthly annual average temperature change graph

Annual dominant wind direction is east and southeast, in addition to the prevailing north wind and northerly winds in winter, the rest of the season are mainly southeast wind and east wind. wind velocity in February-May are relatively high, mainly due to the impact of the northwest wind and spring wind. The rest of the month stabilized at about $1 \mathrm{~m} / \mathrm{s}$. The monthly annual average wind speed curve is shown in Fig. 3, annual wind rose were shown in Fig. 4.

\section{Wind speed $(\mathrm{m} / \mathrm{s})$}

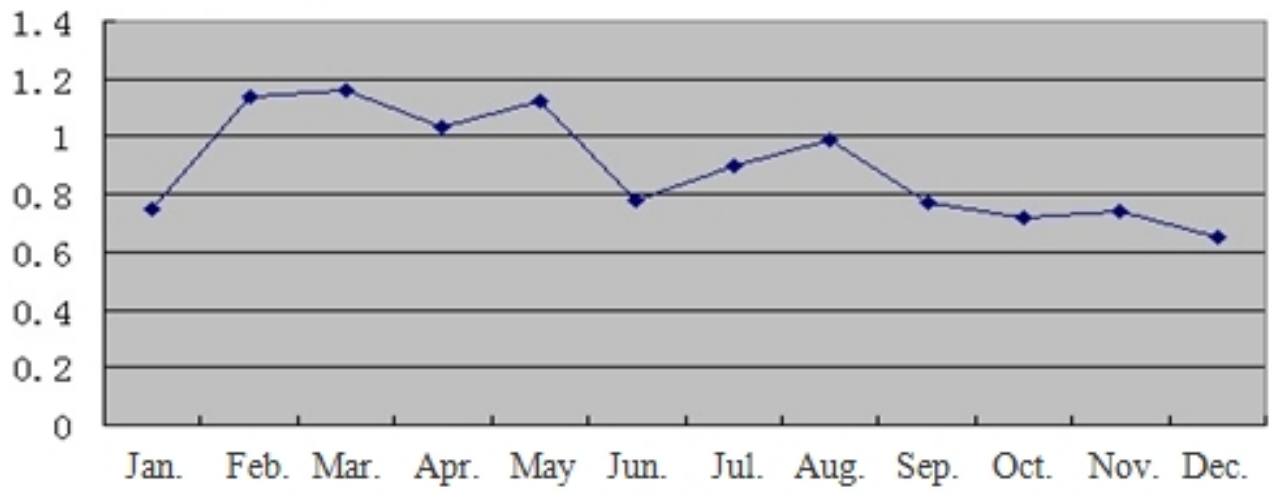

Fig. 3. The annual average wind speed graph of monthly changes 


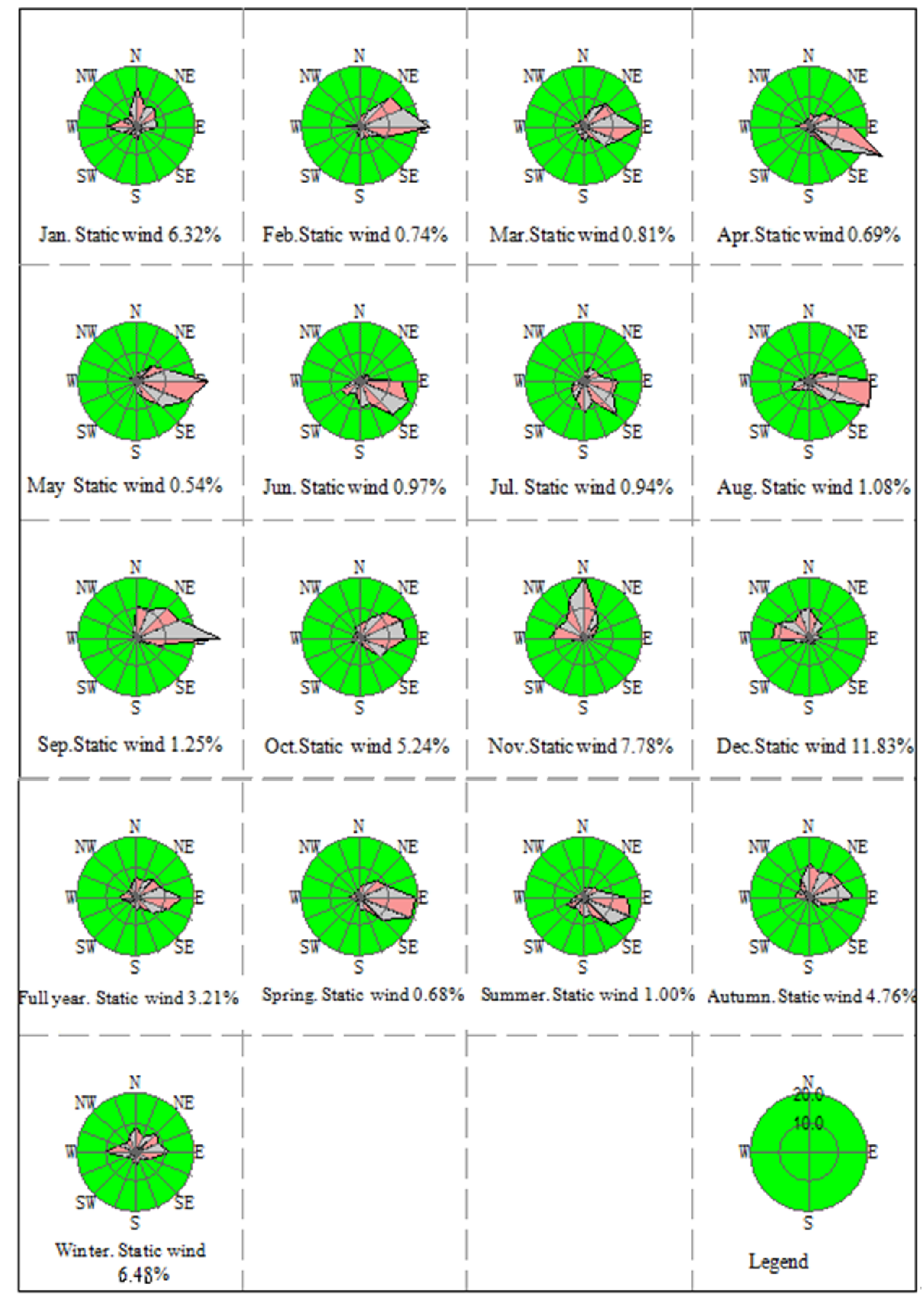

Fig. 4. Annual wind rose

\section{Results of field monitoring}

23 companies have been detected, of which 12 companies found varying degrees of excessive exhaust emissions, Monitoring result shows: 11 of these companies have a serious NMHC exceeded, the highest multiples exceeding 34.2 times, 17 units of odor concentration exceeding seriously, the highest multiples exceeding is 47.9 times. It is worth noting that NMHC exceeded companies' malodor concentrations are also exceeded. By analyzing the no tissue samples of industrial zone and community, we found that characteristic factors and air pollution which enterprises discharge are highly correlated, the main ingredient in ethyl acetate, halogenated solvents and BTEX compounds, butanone, hexane. 


\section{Diffusion factors of malodor pollution}

malodor pollution has a relationship with a number of factors, Including meteorological, wind direction and speed, atmospheric stability, urban environment, urban buildings, even the characteristic of the substance itself, etc., Thus to analyze the spread of malodor, many factors need to be discussed. Let me elaborate on each of these factors to the spread of stench from weather conditions, terrain conditions, conditions of urban architecture aspects ${ }^{[5]}$.

\section{Influence of meteorological conditions on the spread of malodor}

In fact, argumentative malodor pollution is a gas pollution. Diffusion Factors of gas pollution is certainly inseparable from weather conditions, wind speed, wind direction, air temperature, humidity, rain, and atmospheric stability, they have been specifically analyzed below.

\section{Effect of temperature on the diffusion of stench}

Temperature is also one of the factors which affects the diffusion of malodor, the higher the temperature near the ground, the easier the diffusion of convection, making it easier diffusion odor pollutants, on the contrary, the lower the temperature is, the more likely the formation of the inversion layer, so that a stable air mass in a strong state could increase malodor pollution. So from a perspective of season, the winter is easier to form odor pollution, but the large wind in winter had weakened this effect, therefore a relatively low temperature in spring and autumn are more likely to lead to odor pollution; and from the time point of view, the lowest temperature occurs at night, so the most of complaints are at nights.

\section{Effect of wind direction and speed on the diffusion of stench}

Diffusion direction of odor pollution is closely related to the wind direction. General speaking, pollution sources located on the dominant wind direction, and the contaminated areas are located downwind, Yonghewan community and industrial enterprises are complied with this law, so in spring and autumn when the east or southeast wind occurs, odor complaints become more frequent.

Wind speed determine the extent of the spread of the gas diffusion, when wind speed is fast, the malodorous substances mixed with large amounts of clean air, diluting malodor pollutants; wind speed slow, malodorous substances are difficult to spread, prone to odor pollution. As can be seen from the meteorological data, spring has meet both the wind speed conditions and the wind direction conditions, so it is the most frequency season of malodor pollution.

\section{Topography influence on the diffusion of stench in Suzhou Industrial Park}

Suzhou Industrial Park is located in the southeast of Jiangsu Province, and it is in the east of Suzhou city, which is located in the basin area of Yangtze River. Because of the smooth terrain throughout the Suzhou industrial park, there is no significant impact on the proliferation. There are Yangcheng Lake, Jinji Lake, Green Sword Lake, Dushu Lake and other large rivers and lakes in the Suzhou Industrial Park, which may have a negligible impact on the diffusion of malodor pollution.

Residential areas around the lake have more opportunity to be affected by malodor than others, whom are not live near lakes, and the lake surface are generally broad, thus making the dissemination of proliferation stench easily. In addition, the lake winds blowing more humidity, therefore it is easier to be absorbed into the body, which leads to the residents living in the lake for odor pollution complaints more than do not live near a lake ${ }^{[6]}$.

\section{The impact of buildings and urban heat island on diffusion of malodor}

As we all know, the existing of urban would produce urban heat island effect, especially in Suzhou, such a modern metropolis. The so-called heat island effect referring to the climate change phenomenon of the city, due to human activities, the local temperature, humidity, air flow and other factors were changed. It is man-made that caused climate change in the city, so indirectly led to the odor pollution which is difficult to spread in the air, forming a closed, recycling, fume type of pollution. Meanwhile, with the emission of heat in the city, it become more serious that pollution in some areas are worse, leading to the outbreak malodor pollution ${ }^{[7]}$.

Of course, buildings also have a great influence on the diffusion of city's malodor pollution. Suzhou Industrial Park is an area of industrial production, and thus there are many city buildings, public buildings horizontal staggered so that surface roughness is large, so that the flow of air will be slowed 
because of the impact of the building, and the wind speed will low, it is extremely unfavorable for the diffusion of malodorous substances, and even the formation of vortices in an area, resulting in serious malodor pollution in the region, causing local pollution.

\section{Conclusions}

The malodor of Suzhou Industrial Park main from sewage of industrial enterprises, of which the impact of new materials processing industry is more obvious, but the main substance causing malodor concentration in excess are mainly consist of ethyl acetate, halogenated hydrocarbon solvent and BTEX compounds, methyl ethyl ketone, hexane. The factors affecting the diffusion of stench are wind direction and speed, air temperature, precipitation, atmospheric stability, the urban heat island, buildings. The temperature and wind direction and speed are the two most important factors, thus making spring and autumn in the year have more malodor pollution than other seasons, and night is even more prone to lead to diffusion of malodor.

\section{Acknowledgments}

This study was supported by the National Natural Science Foundation Project(31570515), the Science and Technology Support Program of Suzhou(SS201421, SS201523), Environmental Protection Science and Technology Project of Suzhou (2015-3) and the Water Treatment Technology and Materials Collaborative Innovation Project of Jiangsu Universities. It was greatly appreciated, and we were grateful for it.

\section{Reference}

[1] A.P.V. Harreveld. Odor Regulation and the History of Odor Measurement in Europe [M]. Odor Measurement Review, 2003, 54-61.

[2] Jiaomei ZHENG and Xuehua WANG. The Analysis of Odor Pollution Survey Assay and Assessment [J]. Journal of Anhui Agri., 2013, 41(10): 4581-4583.(In Chinese)

[3] Zhiyan JING. Odor and Odor Pollution[J]. Environmental Science Periodicals, 1990, 11(4): 1-11. (In Chinese)

[4] EN13725:2003. Air Quality Determination of Odor Concentration.

[5] Yaqin JI, Li CHEN, Qingchao GONG, Zhao WANG, Shuang GAO, Ying ZHANG and Xiuyan WANG. Malodorous Emission Law and the Method of Sampling and analysis [J]. Environmental Monitoring in China, 2013, 3(29): 132-136.(In Chinese)

[6] G.A. Briggs. Lectures on Air Pollution and Environmental Impact Analysis[J]. Plume rise predictions, 1975, 59-111.

[7] Hengqing MAO and Rong ZHU. Low Temperature Distribution Characteristics of the City and Its Effects on Atmospheric Pollutants Diffusion [J]. Urban Environment and Urban Ecology, 1997, 10(2): 31-35. (In Chinese) 